\title{
Pre-adult development and longevity in natural populations of Lymantria dispar (Lepidoptera: Lymantriidae)
}

\author{
Jelica LAZAREVIĆ, VeSna PERIĆ-MATARUGA and NikOla TUCIĆ
}

Institute for Biological Research, Bulevar Despota Stefana 142, 11000 Belgrade, Serbia; e-mail: jellaz@ibiss.bg.ac.yu

Key words. Lymantriidae, Lymantria dispar, pre-adult development, longevity, stress selection

\begin{abstract}
While most theoretical models for the evolution of ageing assume that duration of pre-adult development does not affect the longevity, experimental data are still controversial and inconsistent. Here we examined the short-term and long-term pattern of pre-adult development time and longevity in populations of the gypsy moth (Lymantria dispar) originating from either oak forest (Quercus petrea), a suitable, or locust-tree forest (Robinia psedoacacia), a poor habitat. Using a full-sib design, we examined the genetic correlations between traits found in larvae reared on oak or locust-tree leaves. We detected only negative and insignificant genetic correlations, except for males from the Robinia population reared on oak leaves where the correlation was negative and significant. Our results also showed that a population living 40 generations in the locust-tree forest exhibited a significantly higher longevity than the Quercus population, whereas a significant difference between these two populations in pre-adult development time does not exist. The results are discussed in relation to the potential effect of stress selection in moulding the longevity of the gypsy moth.
\end{abstract}

\section{INTRODUCTION}

Most contemporary theoretical models for the evolution of ageing assume that duration of pre-adult development does not affect the longevity (reviewed in Finch, 1990; Rose, 1991; Charlesworth, 1994). However, there are still advocates (e.g. Lints, 1988) of the developmental theory of ageing which postulates that, in holometabolous insects, pre-adult development time and lifespan are causally related. According to this hypothesis species-specific ageing and longevity themselves require no evolutionary explanation because they are the components of normal development. Experimental support for this hypothesis was thought to come from studies devoted to the analyses of environmentally induced changes of pre-adult development and adult longevity. However, these studies were highly controversial and inconsistent. Some of them indeed showed that pre-adult development time and adult lifespan are causally related, but there were those indicating autonomy of pre-adult development and senescence (see review in Mayer \& Barker, 1985; Tucić et al., 1998). For example, the first indication of the independence of the length of larval and adult periods stems from the study provided by Northrop (1917) on Drosophila melanogaster: though the larval phases were prolonged twofold by diet restriction, the adult phase was unchanged. Similar conclusions were drawn for early experiments on the gypsy moth. Starvation of caterpillars slowed larval development (about 50\%) without altering the duration of the adult period (Kopec, 1924).

In our previous study with the gypsy moth (Lazarević et al., 1998) we have found two contrasting results with respect to the relationship between pre-adult development and longevity. Females reared on a good host plant (oak leaves) had a significant negative genetic correlation between these two traits, whereas on a marginally suitable host (locust-tree leaves) such correlation was absent (males did not show a significant genetic correlation on either host plant). Since Lymantria dispar is aphagous in the adult stage, the absence of any link between pre-adult and adult stages of development is counterintuitive. Namely, in this holometabolous insect all metabolic reserves are acquired prior to adult eclosion, so that the hypothesis that pre-adult and adult phases might somehow be connected seems a very plausible.

If we accept the view that mechanisms underlying genetic correlations and response to selection are generally the same as those controlling the response to phenotypic manipulations (Partridge, 1992), then it could be predicted that selection for pre-adult development time on the locust-tree leaves will not affect the longevity of the gypsy moth. However, the question arises if environmental manipulations have the same phenotypic effects as genetic variations, which ultimately constrain the evolution of pre-adult development and longevity and other life history traits (Reznick, 1992; Chippindale et al., 1994, Leroi et al., 1994; Tucić et al., 1997).

The best solution for understanding short-term and long-term relationships between pre-adult and adult duration appears to be laboratory evolution experiments (see Rose et al., 1996 for general arguments). In the absence of such experiments, the best strategy is to compare the observed responses of pre-adult development time and longevity to specific changes in the well-known natural habitat and measure the effect on the phenotype by manipulation of this specific agent under the laboratory conditions. Few studies have examined naturally evolved environment-specific differences in longevity and other life history traits (see e.g., Tatar et al., 1997; Gottard et 
al., 2000; Dudycha, 2003). This approach has been adopted in the present study.

Here we investigated the role of pre-adult development in moulding longevity of the gypsy moth in two populations exposed to different environmental conditions. The first population used in this study originated from a mixed, predominantly oak (Quercus petrea), forest. The second population has experienced locust-tree leaves (Robinia pseudoacacia) as the exclusive food resource for about 40 years. Locust-tree leaves are a poor food resource. Therefore the overall aims of the present study were to investigate the evolutionary responses of preadult development time and longevity after extended exposure of the gypsy moth caterpillars to the environmental stress and undertake a comparison of the same traits in a population with favourable food conditions. Such an approach offers an insight into how selection operates in natural systems.

\section{MATERIAL AND METHODS}

\section{Populations and experimental conditions}

The gypsy moth, Lymantria dispar L., is a serious defoliator of forest, shade, and fruit trees in temperate areas of north-west Africa, Europe, Asia and North America (Barbosa, 1978). The moth feeds on over 500 species of trees and shrubs although oaks are ranked as the the preferred food (Lance, 1983).

The gypsy moth is physiologically suited for adult aphagy and females emerge with adequate energy reserves to develop and lay most of their potential eggs. The females lay a single egg mass and fertilization of these eggs is the product of a single mating (Doane, 1968; Rossiter, 1987). Hence, all larvae hatched from a single egg mass represent full-sibs.

Two populations are used in this study, referred to as "Quercus" and "Robinia". The first population (Quercus) was collected in a mixed, predominantly oak (Quercus petrea L.), forest at Despotovačke šume (100 km southeast from Belgrade, Serbia). Thirty egg masses were sampled randomly from oak trees during December 1995. In order to remove pathogens and parasites adhering to their surface, eggs were surface-sterilized in $0.1 \%$ sodium hypochlorite solution for five minutes, rinsed in distilled water for $10 \mathrm{~min}$ and then air dried. These eggs were kept at a temperature of $4^{\circ} \mathrm{C}$ until the end of April the following year when they were ready to hatch.

Eggs were hatched and larvae reared in 200-ml plastic cups at $23^{\circ} \mathrm{C}$ with a $16 \mathrm{~L}: 8 \mathrm{D}$ regime. Five larvae in the first instar but only one or two in the later larval instars were cultured per cup. Fresh leaves (oak or locust-tree) were provided to the larvae daily. Humidity in the cups and the freshness of the leaves were maintained by botanical sponges of $3-4 \mathrm{~cm}^{3}$ soaked with water.

The second population (Robinia) was collected at Bačka Palanka (about $150 \mathrm{~km}$ north-west from Belgrade, Serbia) in the man-made forest consisting only of locust trees (Robinia pseudoacacia L.). The gypsy moth has inhabited this forest (Sidor \& Jodal, 1983) for about 40 years (since the gypsy moth is univoltine species this is also the number of generations). In December 1995, 35 egg masses were sampled randomly from this population and cultured as for the Quercus population.

\section{Measurement of pre-adult development and longevity}

Quercus and Robinia caterpillars from each of collected egg masses (i.e. full-sibs) were divided into two groups: one group was reared on oak leaves and the other on locust-tree leaves. Thus, a split-family two environment experimental design was applied for the analyses of pre-adult development time and adult longevity. The pre-adult development time was defined as the duration (in days) from caterpillars hatching to adult eclosion. The longevity assay was performed using mated pairs in separate cups. The number of dead adults was counted every day. Experiments with each population were performed simultaneously, with all rearing cups randomly distributed in the experimental room.

\section{Data analyses}

By using a mixed-model multiway analysis of variance we tested the significance of the effects of four factors and their interactions on the variation of pre-adult development and longevity. Factors were: population origin (Pop, fixed factor), sex (Sex, fixed), rearing host plant (Host, fixed) and family (Fam, random). Family was nested within population (Fam(Pop)). These sources of fitness-related traits variation pointed to the significance of genetic variation between (Pop) and within the populations (Fam(Pop)), phenotypic plasticity in response to a poor host plant (Host) and sexual dimorphism (Sex). Two-way interaction terms showed the significance of genetic variation in sexual dimorphism within $(\operatorname{Sex} \times$ Fam(Pop) $)$ and between the populations $(\mathrm{Pop} \times \mathrm{Sex})$ and genetic variation in phenotypic plasticity within (Host $\times$ Fam(Pop)) and between the populations (Pop $\times$ Host). According to Jaenike (1981) significant Pop $\times$ Host interaction is statistical evidence for the presence of populationlevel host plant specialization. The biological meaning of Sex $\times \operatorname{Host} \times \operatorname{Fam}($ Pop) interaction is that variation in phenotypic plasticity differs between the sexes while Pop $\times$ Sex $\times$ Host interaction tests if host plant specialization evolved differently in males and females.

All data analyses were performed using SAS, Release 6.06.01 (SAS Institute, 1985). The appropriate ANOVA models (following examination of normality and homogeneity of variance assumption) were applied to $\log$ transformed data. For unbalanced ANOVAs, we used PROC GLM of SAS and Type III sums of squares.

It is important to note that the calculation of appropriate $\mathrm{F}$ values for random factors in a mixed-model ANOVA by SAS tests random factors over their interactions. According to Fry (1992) the result is that, when families (the random factor) are reared on two hosts (the fixed factor) the family effect tested by SAS model reflects the genetic correlation between hosts.

Genetic correlations between pre-adult development and longevity for each population, host plant and sex were calculated from analyses of covariance as genetic covariance between two traits (assigned as $\mathrm{X}$ and $\mathrm{Y}$ ) standardized by their genetic variances

$$
\mathrm{r}_{\mathrm{G}}=\frac{\mathrm{COV}_{\mathrm{G}(\mathrm{XY})}}{\sqrt{\mathrm{V}_{\mathrm{G}(\mathrm{X})^{*}} \mathrm{~V}_{\mathrm{G}(\mathrm{Y})}}}
$$

Broad-sense heritabilities for these traits were calculated from one-way ANOVA (unbalanced full-sib design) according to standard formula

$$
\mathrm{h}^{2}=\frac{2 * \mathrm{~V}_{\mathrm{G}}}{\mathrm{V}_{\mathrm{G}}+\mathrm{V}_{\text {error }}}
$$

\section{RESULTS}

Although pre-adult development time remains longer and the lifespan of females and males shorter on the locust-tree then on the oak leaves, it appears that the gypsy moth population living 40 generations in the locust-tree forest has experienced selection for fast preadult development and longer adult life (Figs 1 and 2). Compared with the Robinia population, females and males from the Quercus population take longer to 


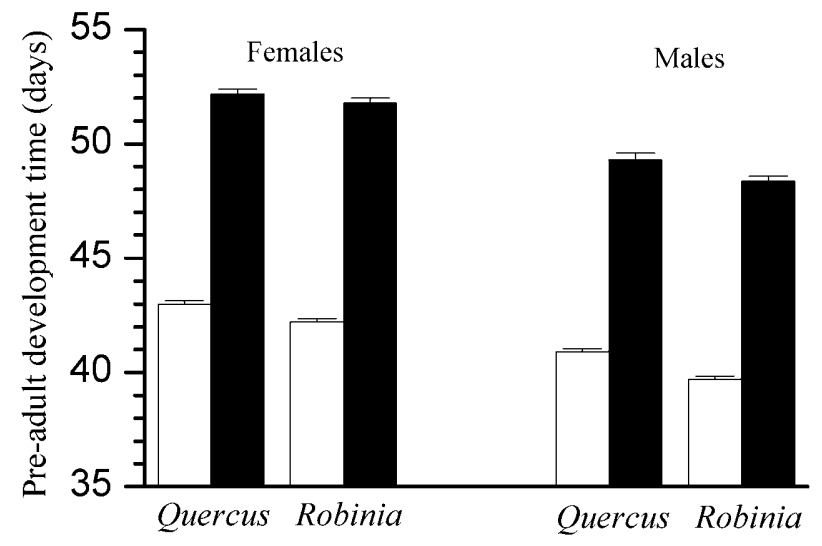

Fig. 1. Pre-adult development time (means and standard errors) of the gypsy moths from Quercus and Robinia populations reared on oak (open bars) and locust-tree leaves (black bars).

develop on both oak and locust-tree leaves. However, significant differences between the Quercus and Robinia populations with respect to pre-adult development time do not exist (Table 1). Since the significant population $x$ host interactions for fitness related traits are thought to be statistical evidence for the presence of population-level host plant specialization, it appears that trophic adaptation in the Robinia population, through shortening of development time of the gypsy moth on a poor host, is not yet fully evolved. In contrast to pre-adult development time, a three-way ANOVA revealed significantly longer lifespan in the Robinia than in the Quercus population (significant Pop effect, $\mathrm{F}_{1,1531}=11.65, \mathrm{P}<0.001$; Table 1). In addition, the longevity data showed a population $\times$ host interaction tending towards significance $\left(\mathrm{F}_{1,1531}=3.68, \mathrm{P}\right.$ $=0.060$; Table 1 ).

A significant family effect was detected only for the pre-adult development time $(\mathrm{P}=0.016$ level $)$. Since the SAS version of the mixed-model ANOVA tests for the among-environment covariance in family means $(\mathrm{F}=$ $\left.\mathrm{MS}_{\mathrm{Fam}(\mathrm{Pop})} / \mathrm{MS}_{\text {Host } \times \text { Fam(Pop) }}\right)$, it follows that this term could

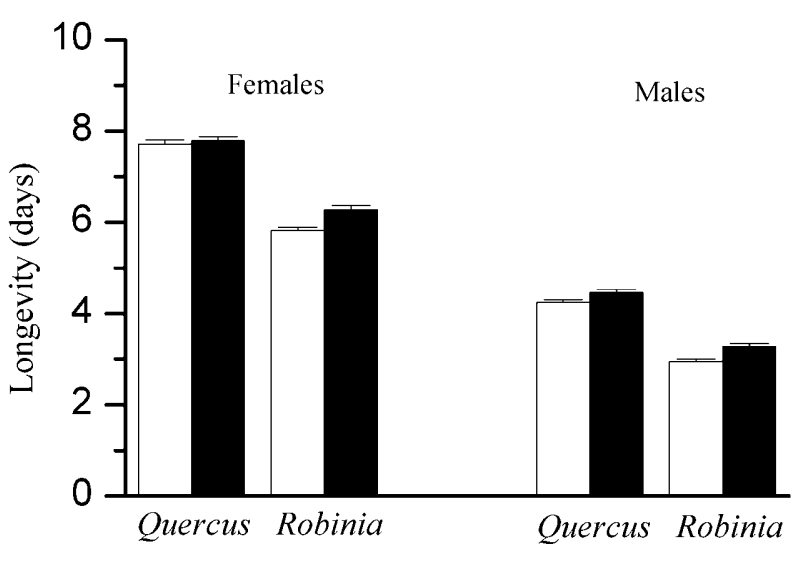

Fig. 2. Longevity (means and standard errors) of the gypsy moth from Quercus and Robinia populations reared on oak (open bars) and locust-tree leaves (black bars).

not be used for testing hypothesis concerning crossenvironment heritability, but for the correlation between the same traits expressed in larvae reared on different food types. However, if an F-test for family effects was computed using the mean square error as the denominator i.e. $\mathrm{F}=\mathrm{MS}_{\mathrm{Fam}(\mathrm{Pop})} / \mathrm{MS}_{\text {Error }}$ ("the Scheffe model", Fry, 1992), genotype sources of variation were found to be highly significant (at the 0.0001 level) for both traits (the $F$ values were 10.13 and 2.34 for pre-adult development time and longevity, respectively).

Significant host $\times$ family interactions were found, again, only for the pre-adult development time (Table 1), suggesting the presence of genetic variation in phenotypic plasticity i.e. sensitivity to poor host leaves. It is interesting to note that both traits exhibited significant $\operatorname{Sex} \times$ Host $\times$ Fam interactions, which indicate that genetic sensitivity to host species are specific for each sex.

The significant three-way interactions Pop $\times \operatorname{Sex} \times$ Host observed only for longevity may be interpreted as follows. Population differentiation with respect to longevity differs between sexes. The significant Pop $\times$ Host interaction was found for females but not for males.

TABLE 1. Mean squares $\left(\times 10^{2}\right)$ from three way ANOVA for pre-adult development time and longevity. Population (Pop), Sex and Host are fixed factors. Family (Fam) is a random factor and is nested within population which is assigned as Fam(Pop). Significant sources of variation are given in bold. $\mathrm{df}=$ degrees of freedom.

\begin{tabular}{|c|c|c|c|c|c|c|}
\hline \multirow{2}{*}{ Source of variation } & \multicolumn{3}{|c|}{ Pre-adult development time } & \multicolumn{3}{|c|}{ Longevity } \\
\hline & MS & $\mathrm{F}$ & $\operatorname{Pr}>F$ & MS & $\mathrm{F}$ & $\operatorname{Pr}>\mathrm{F}$ \\
\hline Pop, $\mathrm{df}=1$ & 1.88 & 2.58 & 0.113 & 28.05 & 11.65 & 0.001 \\
\hline Sex, $\mathrm{df}=1$ & 27.15 & 165.27 & 0.000 & 2928.11 & 1142.57 & 0.000 \\
\hline Host, $\mathrm{df}=1$ & 297.88 & 748.09 & 0.000 & 676.12 & 332.35 & $\mathbf{0 . 0 0 0}$ \\
\hline $\operatorname{Fam}($ Pop. $), \mathrm{df}=63$ & 0.74 & 1.83 & 0.016 & 2.45 & 0.93 & 0.604 \\
\hline Host $\times$ Fam $($ Pop $), d f=63$ & 0.41 & 2.44 & 0.000 & 2.07 & 1.01 & 0.488 \\
\hline Sex $\times$ Fam $($ Pop $), d f=63$ & 0.17 & 1.00 & 0.495 & 2.61 & 1.28 & 0.169 \\
\hline Pop $\times$ Host, $\mathrm{df}=1$ & 0.32 & 0.81 & 0.371 & 7.48 & 3.68 & 0.060 \\
\hline Pop $\times$ Sex, $\mathrm{df}=1$ & 0.16 & 0.98 & 0.327 & 2.27 & 0.88 & 0.351 \\
\hline Sex $\times$ Host $\times$ Fam, $\mathrm{df}=62$ & 0.17 & 2.26 & 0.000 & 2.04 & 1.95 & 0.000 \\
\hline Pop $\times$ Sex $\times$ Host, $\mathrm{df}=2$ & 0.02 & 0.12 & 0.885 & 7.30 & 3.62 & 0.032 \\
\hline Error (df) & \multicolumn{3}{|c|}{$0.07(\mathrm{df}=1607)$} & \multicolumn{2}{|c|}{$1.05(\mathrm{df}=1531)$} & \\
\hline
\end{tabular}


TABLE 2. Heritabilities $\left( \pm\right.$ S.E.) and genetic correlations between pre-adult development time and longevity. $r_{G}=$ genetic correlations calculated on the family variance and covariance components. Significant heritabilities (within each trait) and correlations (within each type of correlation) after making the sequential Bonferroni adjustment (at the 0.05 level) are given in bold.

\begin{tabular}{|c|c|c|c|c|}
\hline & \multicolumn{2}{|c|}{ Quercus population } & \multicolumn{2}{|c|}{ Robinia population } \\
\hline & Oak leaves & Locust-tree leaves & Oak leaves & Locust-tree leaves \\
\hline \multicolumn{5}{|c|}{ Development time } \\
\hline Females & $\mathbf{0 . 5 3 7} \pm 0.158$ & $\mathbf{0 . 8 6 2} \pm 0.166$ & $\mathbf{0 . 7 9 4} \pm 0.159$ & $\mathbf{0 . 4 8 7} \pm 0.139$ \\
\hline Males & $\mathbf{0 . 6 6 5} \pm 0.154$ & $\mathbf{0 . 5 2 9} \pm 0.154$ & $\mathbf{0 . 9 4 1} \pm 0.161$ & $\mathbf{0 . 9 5 7} \pm 0.160$ \\
\hline \multicolumn{5}{|l|}{ Longevity } \\
\hline Females & $0.227 \pm 0.137$ & $\mathbf{0 . 8 1 0} \pm 0.171$ & $\mathbf{0 . 5 6 4} \pm 0.150$ & $0.231 \pm 0.109$ \\
\hline Males & $0.262 \pm 0.120$ & $0.132 \pm 0.108$ & $0.179 \pm 0.109$ & $0.005 \pm 0.071$ \\
\hline \multicolumn{5}{|c|}{ Correlation between traits $\left(\mathrm{r}_{\mathrm{G}}\right)$} \\
\hline Females & $-0.254 \pm 0.283$ & $-0.385 \pm 0.123$ & $-0.019 \pm 0.164$ & $-0.003 \pm 0.264$ \\
\hline Males & $-0.369 \pm 0.201$ & $-0.064 \pm 0.162$ & $\mathbf{- 0 . 9 1 2} \pm 0.041$ & $-3.21 \pm 10.781$ \\
\hline
\end{tabular}

The broad sense heritability estimates for pre-adult development time and longevity are presented in Table 2. Several patterns were apparent. All heritabilities for preadult development time were significantly different from zero, whereas for the longevity data, significant heritability was detected only for the two female groups: Quercus females reared on the locust-tree leaves and Robinia females reared on the oak leaves. It is important to note that all heritability estimates, except those for the male pre-adult development time and longevity in the Quercus population, showed higher values on the novel host. Hence, the genetic variances for pre-adult development time and, to the lesser extent longevity, were lower under conditions that were commonly encountered.

As for the heritabilities, one might expect the correlation structure between pre-adult development and longevity to be host and population dependent. The genetic correlations within each population and host were estimated from one-way random ANCOVA and ANOVA (Table 2). Since we have an indication of sexual differences with respect to the analyzed traits, genetic correlations were determined for females and males separately. In order to reduce the type I error rate among correlation coefficients, we have used a sequential Bonferroni test (Rice, 1989).

The general impression from Table 2 was that signs of the genetic correlation coefficients were negative, indicating that shorter pre-adult development time was accompanied by longer lifespan and vice versa. However, only one of these correlations, for Robinia males reared on oak leaves, was significant. Hence, since we were able to find a significant correlation between pre-adult development time and adult longevity in only one out of eight possible combinations of environment and genotypic frequencies (two populations, two hosts and two sexes), it could be concluded that links between these two periods of the gypsy moth development are absent.

\section{DISCUSSION AND CONCLUSIONS}

The results of the present study suggest that the Quercus and Robinia populations of the gypsy moth have differentiated from each other with respect to adult lon- gevity. A population living for approximately 40 years in the locust-tree forest exhibited significantly higher longevity than the Quercus population (Fig. 2). However, though the observed pre-adult development in the Robinia population was shorter than in the Quercus population (Fig. 1), the statistical confirmation of this trend was absent (Table 1). Similarly, data obtained from the shortterm experiments on the gypsy moth (Northrop, 1917; Kopec, 1924; Lazarević et al., 1998) also indicate the lack of a causal relationship between adult longevities and preadult development length. The short-term experiments and the long-term data derived from natural populations clearly show that the basic tenet of the developmental theory (that pre-adult and adult stages in the holometabolous insects are positively correlated) is not correct for the gypsy moth. Notably, among the genetic correlations from both good and poor environments (Table 2) we find, although insignificant except in one case, only negatively signed coefficients.

How then can the differences between the populations with respect to adult longevity and the absence of appreciable evolutionary response for pre-adult development time in the Robinia population be explained? It could be that in the Robinia population adult longevity was under much stronger selection pressure than pre-adult development time. Nonetheless, it appears that selection on adult longevity could occur in the locust-tree forest. The question is, of course, how aphagous adults experience any direct selection for increased longevity?

The population differences in longevity could have evolved as an indirect effect of adaptation of the gypsy moth to a poor host. A lower nutrient content and a higher tannin, flavinoid and alkaloid content of locust-tree leaves compared to oak leaves (Barbosa \& Kirschnik, 1987) means that the gypsy moth should allocate resources towards energy metabolism and defense rather than towards growth and reproduction. If the unfavourable effect of locust-tree leaves resulted in viability selection, i.e. if only the fittest individuals survive to adults, this increase in mean fitness could be evident in increased adult longevity. Moreover, our earlier observation that gypsy moth larvae reared on locust-tree leaves show 
increased synthesis of glutathione (Perić-Mataruga et al., 1997) suggests that selection in the locust-tree forest is working to maintain defences against the pro-oxidative toxicity of allelochemicals. The increased level of glutathion and other components of the antioxidative defense system raises the possibility that extended longevity of the Robinia gypsy moth resulted through selection for stress resistance. Harman (1956) was the first to formulate the free radical theory of ageing which is based upon the premise that a single common process (free radicals which generate oxidative stress) is responsible for ageing and death. Subsequent authors have had a tendency to define "stress selection" as one of the important determinants of the evolution of life-history traits including longevity (see recent review in Parsons, 2003). For instance, Dudas \& Arking (1995) in Drosophila melanogaster and Šseslija et al. (1999) in Acanthoscelides obtectus, found that extended longevity phenotypes formed by age specific selection showed increased expression of their antioxidant defense system. More generally, resistance to a variety of stressors (eg., starvation, thermal stress, UV stress, anoxia, etc.) is correlated with longevity in many species (Hoffmann \& Parsons, 1991; Parsons, 2003). Thus, if the evolutionary scenario outlined here is correct, stress selection may explain the difference in longevity seen in the Quercus and Robinia populations.

In our previous paper (Lazarević et al., 2002), with the same Quercus and Robinia populations, we found significant population $\times$ host interactions in traits such as pre-adult viability, duration of pupal stage, relative growth rate and gross growth efficiency. These indicate that adaptation of the gypsy moth to a poor host is ongoing, but, if the trophic adaptation means, among other traits, shorter development time on a new host, why did we not observe a significant response to selection for short development in the locust-tree forest?

One possible answer is that forty generations of selection in the locust-tree forest could not produce a significant response because the additive genetic variance for this trait is small. Namely, it is well known from quantitative genetics that if the additive genetic variance of the trait under selection is small, a response is usually obtained when the selection is sustained for very many generations. Rate of development is notorious for its small additive genetic variance (see recent review by Šešlija \& Tucić, 2003). For this reason, artificial selection experiments on holometabolous insects for fast development are often unsuccessful or significantly less successful than for slow development. Data presented in Table 2, which indicate moderate-to-high heritability estimates for pre-adult development and, especially increased values on the locust-tree leaves for the Quercus population, cannot be used as argument against the aforementioned statement. Even though that increased levels of genetic variation are often found during stressful conditions (reviewed in Hoffmann \& Parsons, 1991), the basic reason lies in the fact that these estimates are broad sense heritabilities, i.e. they contain contributions from nonadditive genetic variance, maternal and common- environment effects, with an unknown contribution of additive genetic variance. The additive genetic variances in these estimates are small because, as pointed out by Mather (1973), continued directional selection on a trait would be expected, not only to decrease the additive genetic variance, but to select for increased epistatic genetic variance. Hence, when the genetic basis of a trait is investigated under conditions that are commonly encountered and those that are rarely encountered, epistasis becomes increasingly important in the genetic variance of a trait when measured under novel conditions.

ACKNOWLEDGEMENT. This work was supported by Ministry for Science and Environmental Protection of Serbia, grant \#143033.

\section{REFERENCES}

BARbosa P. 1978: Host plant exploitation by gypsy moth, Lymantria dispar L. Entomol. Exp. Appl. 24: 28-37.

BARBOSA P. \& KRISCHNIK V.A. 1987: Influence of alkaloids on feeding preference of eastern deciduous forest trees by the gypsy moth Lymantria dispar. Am. Nat. 130: 53-69.

Charlesworth B. 1994: Evolution in Age-Structured Populations. Cambridge University Press, Cambridge, xiii +306 pp.

Chippindale A.K., Hoang K.T., Service P.M. \& Rose M.R. 1994: The evolution of development in Drosophila melanogaster selected for postponed senescence. Evolution 48: 1880-1899.

DoAnE C.C. 1968: Aspects of mating behavior in the gypsy moth. Ann. Entom. Soc. Am. 61: 768-773.

DudAS S.P. \& ARKING R. 1995: A coordinate upregulation of antioxidant gene activities is associated with the delayed onset of senescence in a long-lived strain of Drosophila. $J$. Geront. Biol. Sci. (A) 50: B17-B127.

DudYchA J.L. 2003: A multi-environment comparison of senescence between sister species of Daphnia. Oecologia 135: 555-563.

Finch C.E. 1990: Longevity, Senescence and the Genome. University of Chicago Press, Chicago, $922 \mathrm{pp}$.

FRY J.D. 1992: The mixed model analysis of variance applied to quantitative genetics: Biological meaning of the parameters. Evolution 46: 540-550.

GotTHARd K., NYLin S. \& WikLund C. 2000: Mating opportunity and the evolution of sex-specific mortality rates in a butterfly. Oecologia 122: 36-43.

Harman D. 1956: Aging - a theory based on free radical and radiation chemistry. J. Gerontol. 11: 298-300.

Hoffmann A.A. \& Parsons P.A. 1991: Evolutionary Genetics and Environmental Stress. Oxford University Press, Oxford, $\mathrm{ix}+284 \mathrm{pp}$.

JAENIKE J. 1981: Criteria for ascertaining the existence of host races. Am. Nat. 117: 830-834.

KoPEC S. 1924: Studies on the influence of inanition on the development and the duration of life in insects. Biol. Bull. 46: $1-21$.

LANCE D.R. 1983: Host-seeking behavior of the gypsy moth: the influence of polyphagy and highly apparent host plants. In Ahmad S. (ed.): Herbivorous Insects: Host-seeking Behavior and Mechanisms. Academic Press, New York, pp. 210-224.

Lazarević J., Perić-Mataruga V., Ivanović J. \& Andjelković M. 1998: Host plant effects on the genetic variation and correlations in the individual performance of the gypsy moth. Funct. Ecol. 12: 141-148. 
Lazarević J., Perić-Mataruga V., Stojković B. \& Tucić N. 2002: Adaptation of the gypsy moth to an usuitable host plant. Entomol. Exp. Appl. 102: 75-86.

Leror A.M., Kim S.B. \& Rose M.R. 1994: The evolution of phenotypic life-history trade-offs: an experimental study using Drosophila melanogaster. Am. Nat. 144: 661-676.

LinTs F.A. 1988: Genetics. In Lints F.A. \& Soliman M.H. (eds) Drosophila as a Model Organism for Ageing Studies. Blackie, London, pp. 99-118.

Mather K. 1973: Genetical Structure of Population. Chapman \& Hall, London, $197 \mathrm{pp}$.

MAYer P.J. \& BARKER G.T. 1985: Genetic aspects of Drosophila as a model system of eukaryotic ageing. Int. Rev. Cytol. 95: $61-102$.

NoRThrop J.K. 1917: The effect of prolongation of the period of growth on the total duration of life. J. Biol. Chem. 32: 123-126.

PARSONS P.A. 2003: From the stress theory of aging to energetic and evolutionary expectations for longevity. Biogerontology 4: 63-73.

PARTRIDGe L. 1992: Measuring reproductive costs. Trends Ecol. Evol. 7: 99-100.

Perić-Mataruga V., Blagojević D., Spasić M.B., Ivanović J. \& JANKOVIĆ-HLADNI M. 1997: Effect of the host plant on the antioxidative defense in the midgut of Lymantria dispar L. caterpillars of different population origins. J. Insect Physiol. 43: $101-106$

ReZNICK D. 1992: Measuring the costs of reproduction. Trends Ecol. Evol. 7: 44-55.

RicE W.R. 1989: Analyzing tables of statistical tests. Evolution 43: $223-225$.

Rose M.R. 1991: Evolutionary Biology of Aging. Oxford University Press, Oxford.
Rose M.R., Nusbaum T.J. \& Chippindale A.K. 1996: Laboratory evolution: The experimental wonderland and the Cheshire cat syndrome. In Rose M.R. \& Lauder G.V. (eds): Adaptation. Academic Press, San Diego, pp. 221-241.

Rossiter M.C. 1987: Genetic and phenotypic variation in diet breadth in a generalist herbivore. Evol. Ecol. 1: 272-282.

ŠEšLIJA D. \& Tucić N. 2003: Selection for developmental time in bean weevil (Acanthoscelides obtectus): Correlated responses for other life history traits and genetic architecture of line differentiation. Entomol. Exp. Appl. 106: 19-35.

Šešlija D., Blagojević D., Spasić M., Tucić N. 1999: Activity of superoxide dismutase and catalase in the bean weevil (Acanthoscelides obtectus) selected for postponed senescence. Exp. Geront. 34: 185-195.

Sidor C. \& Jodal I. 1983: Results of investigations of health conditions of gypsy moth (Porthetria dispar) in acacia forest Bagremara. Plant Prot. (Belgrade) 34: 445-455.

Tatar M., Gray D.W. \& Carey J.R. 1997: Altitudinal variation for senescence in Melanoplus grasshoppers. Oecologia 111: 357-364.

Tucić N., Stojković O., Gliksman I., Milanović D. \& Šelija D. 1997: Laboratory evolution of life history traits in the bean weevil (Acanthoscelides obtectus): the effects of densitydependent and age-specific selection. Evolution 51: 1894-1907.

Tucić N., Gliksman I., Šelija D., Stojković O. \& Milanović D. 1998: Laboratory evolution of life-history traits in the bean weevil (Acanthoscelides obtectus): the effects of selection on developmental time in populations with different previous history. Evolution 52: 1713-1725.

Received May 4, 2006; revised and accepted December 19, 2006 